Article

\title{
Flotation and Adsorption of a New Polysaccharide Depressant on Pyrite and Talc in the Presence of a Pre-Adsorbed Xanthate Collector
}

\author{
Wei Deng ${ }^{1,2}$, Longhua $\mathrm{Xu}{ }^{3,4,5, *}$, Jia Tian ${ }^{2}$, Yuehua $\mathrm{Hu}^{4}$ and Yuexin Han ${ }^{1, *}$ \\ 1 College of Resources and Civil Engineering, Northeastern University, Shenyang 110819, China; \\ neudengwei@163.com \\ 2 Institute of Multipurpose Utilization of Mineral Resources, Chinese Academy of Geological Science, \\ Chengdu 610041, China; swusttianjia@163.com \\ 3 Key Laboratory of Solid Waste Treatment and Resource Recycle Ministry of Education, \\ Southwest University of Science and Technology, Mianyang 621010, China \\ 4 School of Resources Processing and Bioengineering, Central South University, Changsha 410083, China; \\ hyh@csu.edu.cn \\ 5 State Key Laboratory of Mineral Processing, Beijing 102628, China \\ * Correspondence: neuxulonghua@163.com (L.X.); dongdafulong@mail.neu.edu.cn (Y.H.)
}

Academic Editor: William Skinner

Received: 7 February 2017; Accepted: 15 March 2017; Published: 16 March 2017

\begin{abstract}
The flotation and adsorption of a new polysaccharide konjac gum (KG) on pyrite and talc in the presence of pre-adsorbed potassium butyl xanthate (PBX) is investigated. The micro-flotation results show that KG is a quality depressant for talc and that conditioning the minerals initially with PBX before KG will increase the recovery difference between pyrite and talc. The results of artificially mixing the minerals show that compared with adding $\mathrm{KG}$ before $\mathrm{PBX}$, when minerals are pre-adsorbed with PBX, the grade and the recovery of sulfur (S) increases by $1.96 \%$ and $5.44 \%$, respectively. The contact angle results show that the addition of PBX before KG will increase the contact angles of pyrite, but the addition order of KG/PBX has little influence on the contact angles of talc. The adsorption tests show that KG can adsorb on pyrite and talc surfaces, while PBX can only adsorb on the pyrite surface. The addition order of KG/PBX affects the adsorption of KG and PBX on the pyrite surface but not on the talc surface. Fourier transform infrared (FTIR) spectra analysis further demonstrates the chemical adsorption of KG on pyrite and talc surfaces, while PBX chemisorbs on the pyrite surface. Based on these analyses, a schematic illustration of the reagent adsorption forms on pyrite and talc surfaces is drawn to explain the competitive adsorption of KG and PBX on mineral surfaces.
\end{abstract}

Keywords: pyrite; talc; addition order; konjac gum; competitive adsorption

\section{Introduction}

Magnesium silicates, including talc, chlorite and serpentine, are the main gangue components of metal sulfide ore deposits [1-3]. The presence of these gangue minerals at high concentrations will not only increase the smelting cost but will also reduce the smelting efficiency [4,5]. Talc, with its excellent natural hydrophobicity, has been universally researched as the typical gangue mineral during sulfide mineral flotation [6-8]. To prevent the interference of talc during sulfide mineral flotation, previous research has mainly focused on introducing a suitable depressant.

For many years, many publications have been focused on investigating the inhibitory effect of polysaccharides during the flotation of sulfide minerals. Compared with the highly toxic inorganic modifiers, polysaccharides have significant advantages due to their nontoxic and selective inhibition 
properties [7-9]. It has been shown that the adsorption difference of Dextrin-WY on sulfide minerals and on the talc surface resulted in different densities of hydroxyl groups that were exposed to solution [4]. Additionally, the research showed that the molecular weight was a significant factor that affected the performance of polymers, and the larger molecular weight polymers were more selective towards hydrophilic gangue minerals at starvation dosage [10-13]. In industry, guar gum is the most widely used depressant for hydrophobic gangue minerals. However, it still has drawbacks such as high cost and limited availability $[5,8,13,14]$. To identify more economical depressants, attempts have been made by researchers to investigate new depressants such as galactomannan and foenum-graecum that are easier to obtain, have a high depression selectivity for magnesium silicates and little depression effect on nickel minerals [5,15]. In this study, we would like to introduce a new polysaccharide depressant, konjac gum (KG), that is extracted from konjac, which is widely planted in the southwest and midwest of China. Compared with guar gum, konjac gum is more economical and more selective for the flotation separation of nickel-copper minerals [16]. Most importantly, the research on the depressive effect of konjac gum and the adsorption mechanism of konjac gum on minerals has not been previously reported.

Traditionally, to exert the effect of a depressant, the depressant must be added before the collector. Thus, the depressant will first adsorb on the surface of the minerals. Inevitably, the depressant will adsorb on the metal sulfide minerals and affect the adsorption of collectors [8]. Thus, it is imperative to find a way to maximize the inhibition effect of depressants on magnesium silicates without depressing metal sulfide minerals. Feng et al. [17] found that the order of addition between potassium and carboxymethyl cellulose significantly affects the flotation separation of pyrite and chlorite, but the underlying mechanism was not identified. Xanthate has been used for a long time as a collector for metal sulfide minerals. Previous research showed that for the flotation of pyrite, the ferric irons on the pyrite surface serve as the active sites for adsorbing xanthate molecules $[16,18]$.

In this study, we first investigated the adsorption mechanism of konjac gum on pyrite and talc surface and, second, studied the separation performance of konjac gum on pyrite and talc in the presence of pre-adsorbed xanthate collector. The study will provide a new idea for the flotation separation process in depressants and collector coexisting systems.

\section{Experimental}

\subsection{Materials and Reagents}

Pure pyrite and talc samples are obtained from Yunfu in the Guangdong Province (China) and Haicheng in the Liaoning Province (China), respectively. After being handpicked, crushed, ground and screened, the powder samples of $-75+38 \mu \mathrm{m}$ fractions were used in flotation tests. The samples that were used for the Fourier transform infrared (FTIR) analysis measurement were further ground to approximately $-20 \mu \mathrm{m}$. The chemical composition and X-ray diffractometry (PANalytical B.V., Almelo, The Netherlands) of pyrite and talc that were used to study the chemical characteristics and mineral compositions are shown in Table 1 and Figure 1. The chemical analysis results show that the purity of as-prepared pyrite and talc is greater than $90 \%$. The mass ratio of pyrite and talc is $2: 3$ in the artificially mixed minerals.

Table 1. Chemical composition of the purified samples (mass fraction, \%).

\begin{tabular}{ccccccc}
\hline Sample & $\mathrm{SiO}_{2}$ & $\mathbf{M g O}$ & $\mathrm{CaO}$ & $\mathrm{Al}_{2} \mathrm{O}_{\mathbf{3}}$ & $\mathrm{Fe}_{2} \mathrm{O}_{\mathbf{3}}$ & $\mathbf{S}$ \\
\hline Talc & 61.42 & 31.40 & 5.12 & - & 1.06 & - \\
Pyrite & 4.67 & 0.67 & 0.62 & 2.05 & 30.73 & 53.00 \\
\hline
\end{tabular}

The depressant KG is extracted from konjac gum and is supplied by the Institute of Multipurpose Utilization of Mineral Resources Flotation Reagents Limited Company, Chengdu, China. Potassium butyl xanthate (PBX) is used as a collector, methyl isobutyl carbinol (MIBC) is used as a frother, and hydrochloric acid $(\mathrm{HCl})$ and sodium hydroxide $(\mathrm{NaOH})$ are used as $\mathrm{pH}$ regulators. 
All of these reagents are chemically pure. Deionized water (Resistivity $=18.3 \mathrm{M} \Omega \cdot \mathrm{cm}$ ) is used for the micro-flotation tests.
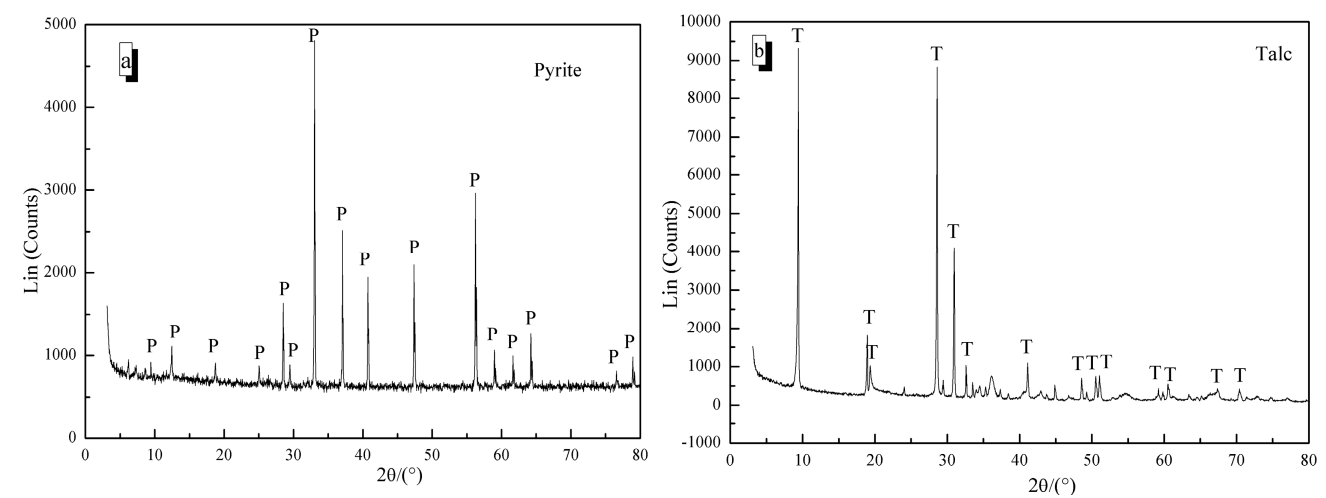

Figure 1. XRD patterns of the purified samples: (a) pyrite; $(\mathbf{b})$ talc $(\mathrm{P}=$ pyrite, $\mathrm{T}=$ talc).

\subsection{Flotation Tests}

Both the single mineral ( $3 \mathrm{~g})$ microflotation and the artificial mixed mineral $(3 \mathrm{~g})$ flotation were conducted in a $40 \mathrm{~mL}$ hitch groove flotation cell with a spindle speed of $1600 \mathrm{r} / \mathrm{min}$. The flotation machine for microflotation tests was shown in Figure 2. The artificial mixed minerals consisted of $1.2 \mathrm{~g}$ of pyrite and $1.8 \mathrm{~g}$ talc, and the corresponding sulfur (S) and $\mathrm{MgO}$ grades of the artificially mixed minerals were $21.20 \%$ and $18.84 \%$, respectively. The desired amount of KG, PBX and MIBC were added to the slurry in a corresponding order, and the slurry was conditioned for $10 \mathrm{~min}, 3 \mathrm{~min}$ and $2 \mathrm{~min}$, respectively. The microflotation was conducted for $4 \mathrm{~min}$. The froth products and tails were weighed separately after the filtration and drying, and the recovery was calculated based on the dry weight of the product. The flotation grades of pyrite and talc were assessed via chemical analysis in artificially mixed mineral flotations. Each experiment was repeated three times, and the average was reported as the final value. Standard deviation, which is presented as an error bar, was calculated using Origin 9.2 (OriginLab, Hampton, VA, USA) based on the three measurements.

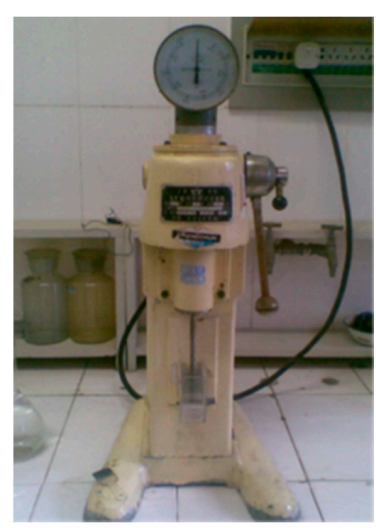

Figure 2. Flotation machine for the microflotation test.

\subsection{Contact Angle Measurements}

The contact angles were measured using DSA 30 from KRUSS, Inc., Hamburg, Germany. After being washed thoroughly with water, the pure single crystal pyrite and talc were conditioned with $0.2 \mathrm{mM}$ of reagent at $25{ }^{\circ} \mathrm{C}$ for $30 \mathrm{~min}$. Then, the sessile liquid drop technique was used to measure the contact angles of the samples. Prior to each measurement, the sample had to be repolished and conditioned with reagents. $\mathrm{HCl}$ and $\mathrm{NaOH}$ were used to adjust the $\mathrm{pH}$ of the solution. Each final result is the average of five measurements. 


\subsection{Adsorption Measurements}

The adsorption test samples were prepared by adding $1 \mathrm{~g}$ of a single mineral and $100 \mathrm{~mL}$ of a desired concentration of reagents to $250 \mathrm{~mL}$ Erlenmeyer flasks. Because the study was to investigate the effect of the order of reagent addition on the adsorption of reagents on mineral surfaces, KG was added either before or after PBX and was conditioned for $10 \mathrm{~min}$. The prepared suspension was placed on a rotator for $1 \mathrm{~h}$ to ensure that the adsorption process was completely carried out. After being centrifuged, the concentration of the reagents that were left in the solution was analyzed using the UV absorbance (Thermo Fisher Scientific Inc., Waltham, MA, USA) at $300 \mathrm{~nm}$. The amount of reagents that were depleted from the solution was assumed to be adsorbed onto the particular mineral phase.

\subsection{FTIR Measurements}

Fourier transform infrared (FTIR) spectra were recorded using a Spectrum one (Version BM) FT-IR (PerkinElmer, Waltham, MA, USA) spectrometer at $25^{\circ} \mathrm{C}$ in the 4000 to $450 \mathrm{~cm}^{-1}$ range. The spectra of the solids were acquired using $\mathrm{KBr}$ pellets. Prior to the test, pure minerals were grounded to less than $2 \mu \mathrm{m}$ in an agate mortar. Then, the purified mineral particles $(2.0 \mathrm{~g})$ and the desired reagents were placed in a plexiglass cell with $40 \mathrm{~min}$ of conditioning time. Next, the solid samples were washed three times using ultrapure water. Finally, the washed samples for FTIR analysis were vacuum dried at a temperature below $60^{\circ} \mathrm{C}$.

\section{Results and Discussion}

\subsection{Microflotation Results}

Figure 3 shows the effect of $\mathrm{pH}$ on the microflotation recovery of pyrite and talc. The recovery of pyrite is relatively high under acidic and neutral $\mathrm{pH}$ conditions. Under alkaline $\mathrm{pH}$ conditions, the recovery of pyrite decreases gradually from $83.79 \%$ at $\mathrm{pH} 6.87$ to $64.41 \%$ at $\mathrm{pH} 11.68$. The decline in pyrite microflotation recovery under strong alkaline conditions is due to the formation of a hydrophilic ferric hydroxide film on the pyrite surface, which inhibits the flotation of pyrite [8]. The recovery of talc with or without the presence of the collector PBX is compared in Figure 3. It is apparent that the slurry $\mathrm{pH}$ has little effect on the microflotation recovery of talc. In the presence of collector PBX, talc yields a high flotation recovery of approximately $90 \%$ over the entire $\mathrm{pH}$ range. In the absence of the collector, over the investigated $\mathrm{pH}$ range, talc still exhibits an excellent flotation recovery of approximately $90 \%$ with the MIBC foamer alone.

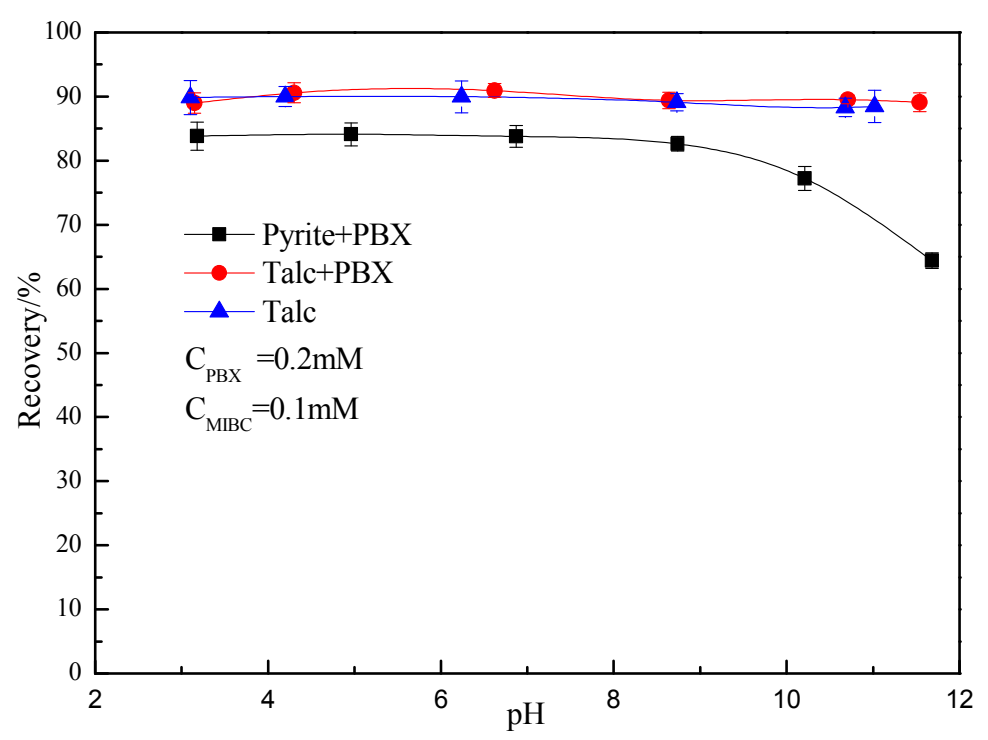

Figure 3. Effect of $\mathrm{pH}$ on the microflotation recovery of pyrite and talc. 
Figure 4 presents the effect of PBX concentration on the flotation recovery of pyrite and talc. In the absence of the collector PBX, the flotation recovery of pyrite is only approximately $20 \%$. However, with the increase of PBX concentration, the recovery of pyrite increases rapidly and reaches a maximum value of $83 \%$ at a PBX concentration of $2 \times 10^{-4} \mathrm{~mol} / \mathrm{L}$. After reaching the maximum recovery value, the continual increase of PBX concentration only results in an insignificant increase of pyrite recovery. Unlike pyrite, the flotation recovery of talc is independent of PBX concentration and remains as much as $90 \%$.

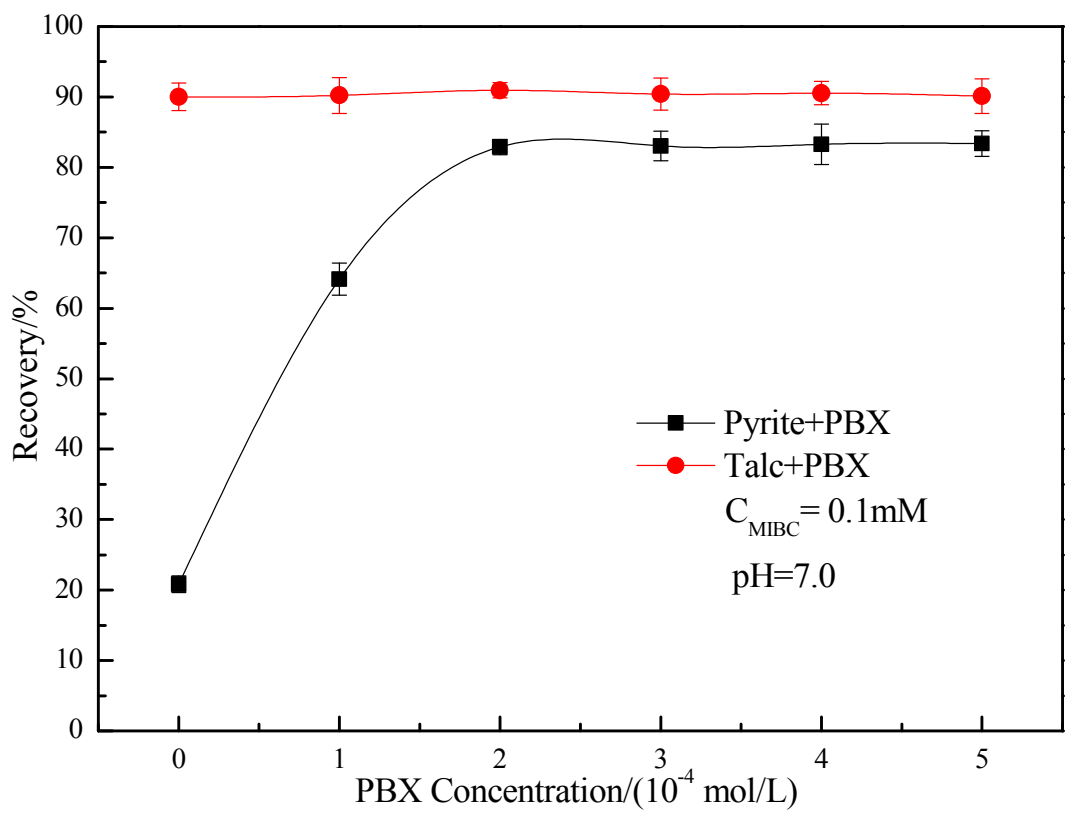

Figure 4. Effect of PBX concentration on the microflotation recovery of pyrite and talc.

Figures 3 and 4 together show that talc is naturally floatable and has better floatability than pyrite in the presence of PBX and MIBX. To realize the flotation separation of pyrite from talc, it is imperative to introduce the depressant KG to inhibit the flotation of talc. Figure 5 shows the effect of KG concentration on the flotation recovery of pyrite and talc. It is obvious that KG is a quality depressant for talc. When the KG concentration is increased, the recovery of talc sharply decreases. At KG concentration of $35 \mathrm{mg} / \mathrm{L}$, the recovery of talc decreases from the original $90 \%$ to $12 \%$. Compared with the notable decrease of talc recovery, the change in pyrite recovery is not that obvious but still decreases from the original $83 \%$ to $60 \%$ with $35 \mathrm{mg} / \mathrm{L}$ of $\mathrm{KG}$.

Figure 6 shows the effect of KG/PBX addition order on the microflotation recovery of pyrite (a) and talc (b). As we can see in Figure 6a, there is an apparent gap in pyrite recovery between the PBX and KG coexisting system and the single PBX system. Interestingly, the addition order of KG/PBX has a noticeable effect on the microflotation recovery of pyrite. When the depressant KG is added before the collector PBX, the recovery of pyrite is only $60 \%$ at a PBX concentration of $4 \times 10^{-4} \mathrm{~mol} / \mathrm{L}$. However, when pyrite is pre-adsorbed with the collector PBX, the recovery of pyrite is higher than when $K G$ is added before $\mathrm{PBX}$ over the entire concentrate range and reaches as much as $80 \%$ at a $\mathrm{PBX}$ concentration of $4 \times 10^{-4} \mathrm{~mol} / \mathrm{L}$. It is evident from Figure $6 \mathrm{~b}$ that the addition order of KG/PBX has little influence on the microflotation recovery of talc. Whether KG is added before or after PBX, the floatability of talc is significantly inhibited by KG. In fact, it does not matter whether KG is added or not, the microflotation recovery of talc shows little difference. In summary, by controlling the addition order of $\mathrm{KG} / \mathrm{PBX}$, we can strengthen the flotation separation of pyrite from talc. 


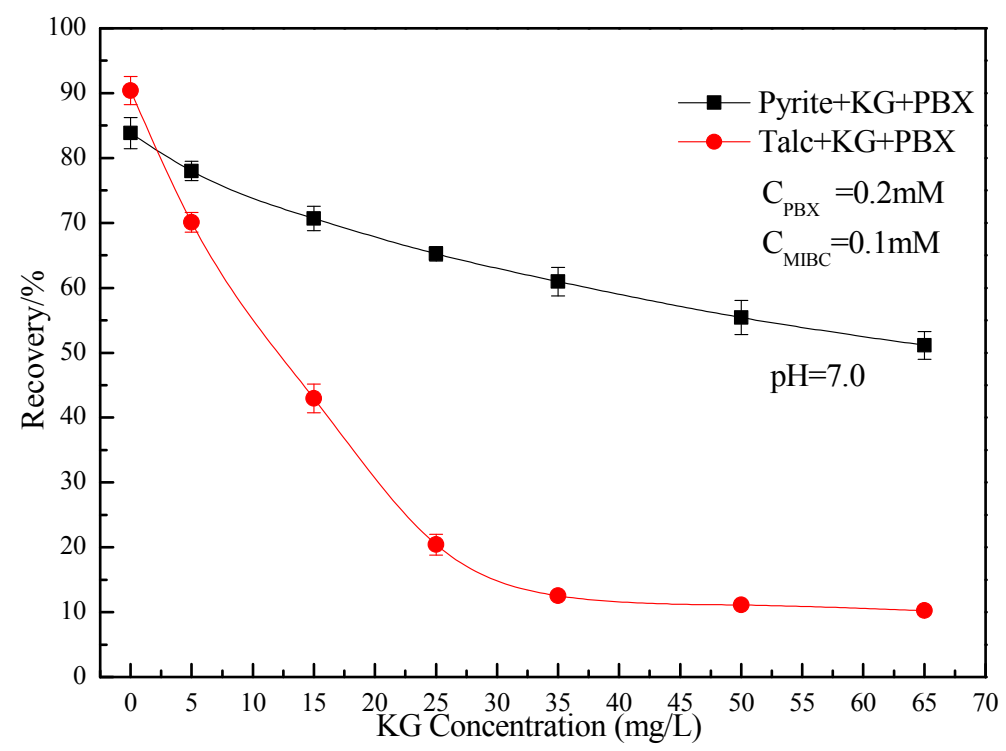

Figure 5. Effect of konjac gum (KG) concentration on the microflotation recovery of pyrite and talc.
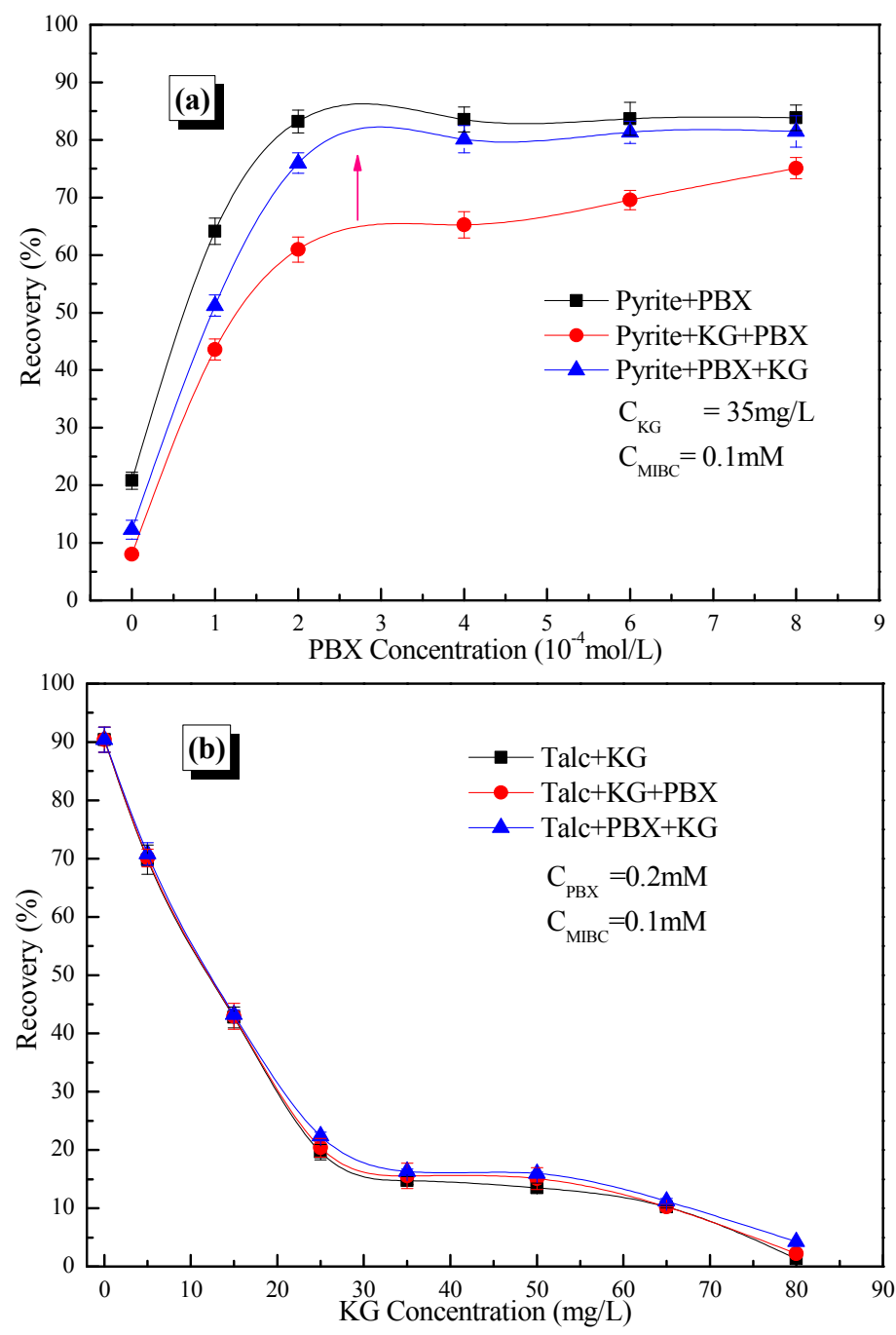

Figure 6. Effect of the KG/potassium butyl xanthate (PBX) addition order on the microflotation recovery of pyrite (a) and talc (b). 


\subsection{Artificially Mixed Minerals Results}

To further investigate the effect of the KG/PBX addition order on the flotation recovery of pyrite and talc, the artificially mixed mineral experiments were carried out. Table 2 shows the flotation results of artificially mixed minerals. In the absence of the depressant KG, both the recovery of $S$ and the content of $\mathrm{MgO}$ in the concentrate are very high, which indicates that pyrite and talc are all floated. Thus, the flotation separation of pyrite from talc cannot be realized. When KG is added before PBX, the grade of $\mathrm{S}$ in the concentrate increases from the original $21.20 \%$ to $33.79 \%$. At the same time, the content of $\mathrm{MgO}$ and the recovery of S decrease by $13.67 \%$ and $8.93 \%$, respectively. However, when the minerals are pre-adsorbed with the collector PBX, compared with the former addition order, the grade and the recovery of $\mathrm{S}$ increase by $1.96 \%$ and $5.44 \%$, respectively; the grade of $\mathrm{S}$ increases further by $1.96 \%$, while the content of $\mathrm{MgO}$ in the concentrate decreases further from $4.30 \%$ to $3.52 \%$. The artificially mixed mineral results further prove that adding PBX before KG will strengthen the flotation separation of pyrite from talc.

Table 2. Flotation results of artificially mixed minerals. (PBX concentration of $2 \times 10^{-4} \mathrm{~mol} / \mathrm{L}$; methyl isobutyl carbinol (MIBC) concentration of $1 \times 10^{-4} \mathrm{~mol} / \mathrm{L} ; \mathrm{KG}$ concentration of $35 \mathrm{mg} / \mathrm{L}$ ).

\begin{tabular}{ccccccc}
\hline \multirow{2}{*}{ Reagent System } & \multirow{2}{*}{ Product } & Yield/\% & \multicolumn{2}{c}{ Grade/\% } & \multicolumn{2}{c}{ Recovery/\% } \\
\cline { 3 - 6 } & & & S & MgO & S & MgO \\
\hline \multirow{3}{*}{ PBX } & Concentrates & 80.36 & 23.72 & 17.97 & 89.91 & 76.65 \\
& Tailing & 19.64 & 10.89 & 22.40 & 10.09 & 23.35 \\
& Feed & 100.00 & 21.20 & 18.84 & 100.00 & 100.00 \\
\hline \multirow{2}{*}{ KG + PBX } & Concentrates & 50.81 & 33.79 & 4.30 & 80.98 & 11.59 \\
& Tailing & 49.19 & 8.20 & 33.86 & 19.02 & 88.41 \\
& Feed & 100.00 & 21.20 & 18.84 & 100.00 & 100.00 \\
\hline \multirow{2}{*}{ PBX + KG } & Concentrates & 51.25 & 35.75 & 3.52 & 86.42 & 9.56 \\
& Tailing & 48.75 & 5.90 & 34.95 & 13.58 & 90.44 \\
& Feed & 100.00 & 21.20 & 18.84 & 100.00 & 100.00 \\
\hline
\end{tabular}

\subsection{Contact Angle Results}

Contact angle measurement is an important method for investigating the wettability nature of reagents on the pyrite and talc surfaces [19]. Figure 7a,b illustrate the effect of the KG/PBX addition order on the flotation recovery of pyrite and talc, respectively. As we can see in Figure 7a, in the absence of the depressant $K G$, the contact angle of pyrite increases with the increase of PBX concentration. This means that the hydrophobicity of pyrite is gradually enhanced. When the collector $\mathrm{PBX}$ concentration is $4 \times 10^{-4} \mathrm{~mol} / \mathrm{L}$, the contact angle of pyrite increases to $75^{\circ}$. In the $\mathrm{KG}$ and PBX coexisting system, the contact angle of pyrite is smaller than that in the single PBX system over the entire investigated PBX concentrations. Especially, when KG is added before PBX, the contact angle of pyrite is clearly reduced, indicating that the hydrophobicity of pyrite is weakened. When pyrite is pre-absorbed with PBX, the contact angle of pyrite is still smaller than that in the single PBX system and is much higher than that when KG is added before PBX. It can be inferred from the contact angle measurements of pyrite that, compared with treating pyrite in a traditional way, the addition of PBX before $\mathrm{KG}$ enhances the hydrophobicity of pyrite.

It is seen in Figure $7 \mathrm{~b}$, in the absence of the depressant $\mathrm{KG}$, that the contact angles of talc remain, on average, at $77^{\circ}$ in the investigated concentration ranges, which further proves the excellent hydrophobicity of talc. In the KG and PBX coexisting system, regardless of whether KG is added before or after PBX, the contact angles of talc are distinctly reduced compared with the single PBX system. Nevertheless, an insignificant contact angle difference is observed when KG and PBX are added in different orders. The contact angle measurements are in agreement with the micro-flotation results. It can be inferred from these results that the addition of PBX before KG will 
sharply reduce the hydrophobicity of talc and will clearly enhance the hydrophobicity of pyrite. Thus, the wettability difference of pyrite and talc is increased, and the flotation separation of pyrite from talc becomes feasible.
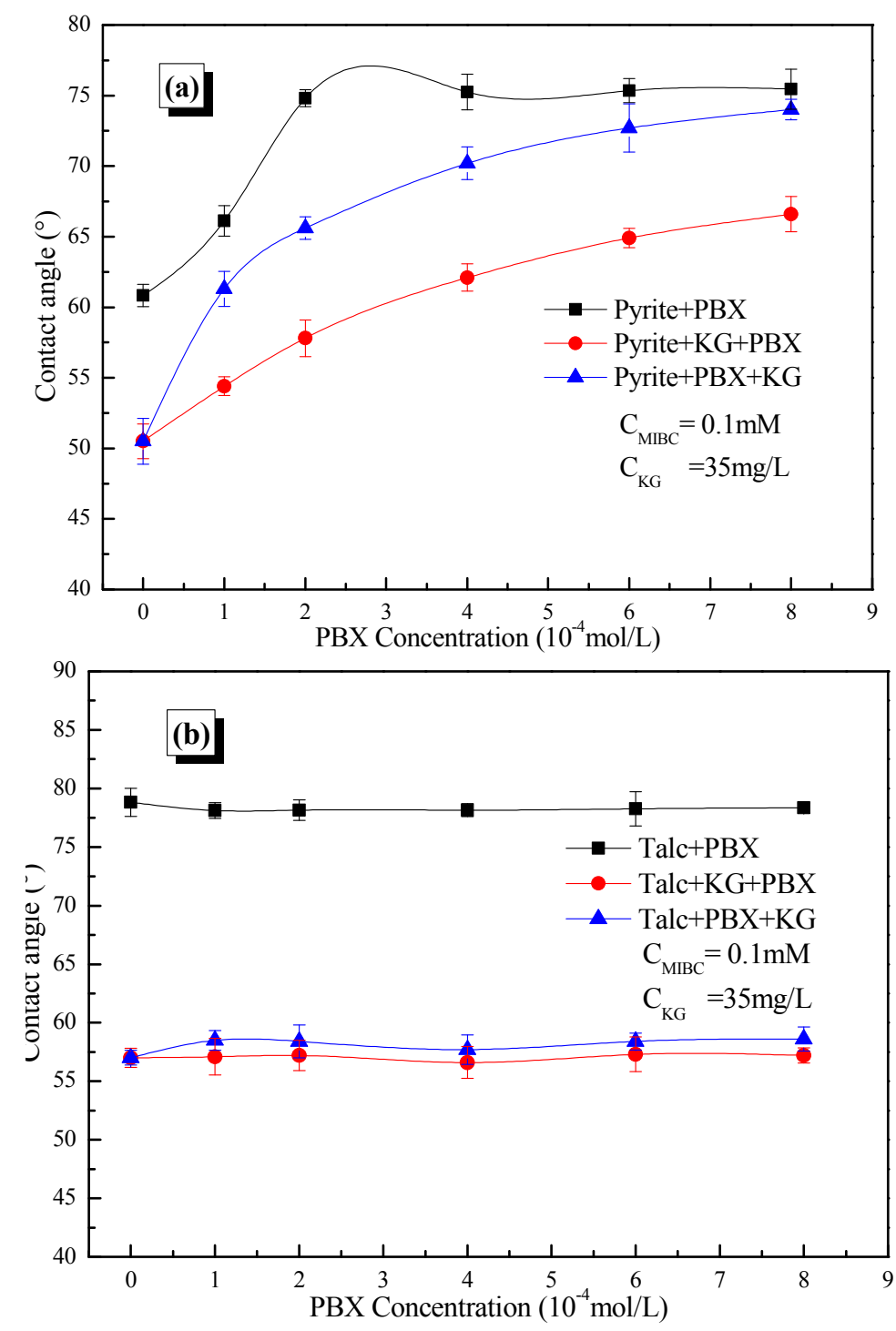

Figure 7. Effect of the KG/PBX addition order on the flotation recovery of pyrite (a) and talc (b).

\subsection{Adsorption Test Results}

As the direct approach for reflecting the adsorption amount difference of reagents on the mineral surfaces, adsorption tests are applied universally to provide guidance for the analysis of flotation separation [20]. Figure 8a,b show the effect of the KG/PBX addition order on the adsorption of PBX on pyrite and talc surfaces, respectively. From Figure 8a, it is seen that regardless of the approach used to add the reagents, the adsorption of PBX on the pyrite surface increases with the increase of PBX concentration. Clearly, compared with treating pyrite in a traditional way, the adsorption of PBX on the pyrite surface will increase when pyrite is pre-adsorbed with PBX over the entire concentration range. However, Figure $8 \mathrm{~b}$ shows that the addition order of KG/PBX has no effect on the adsorption of PBX on the talc surface. Regardless of which method is used to treat pyrite, no PBX is observed on the talc surface. 

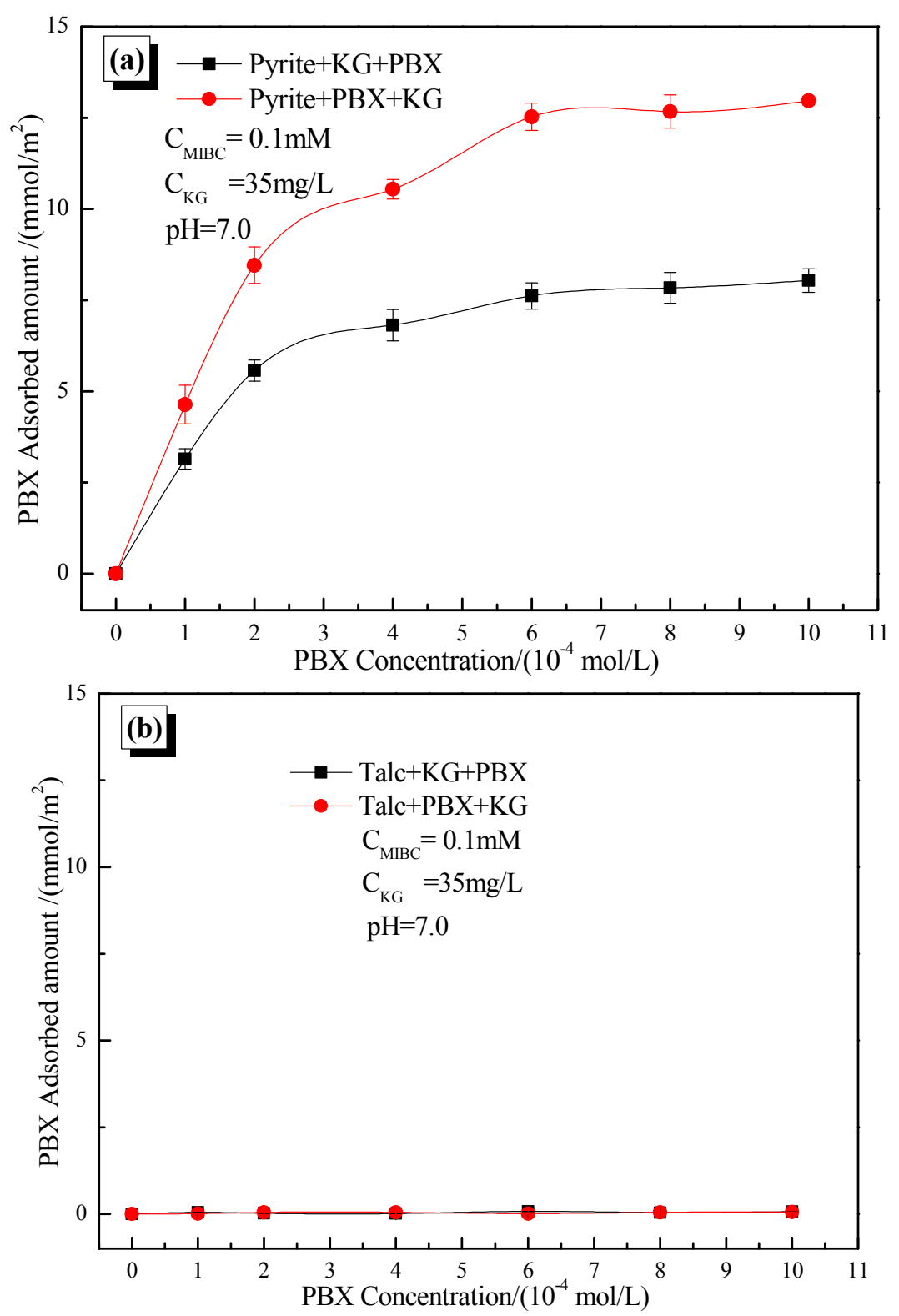

Figure 8. Effect of the KG/PBX addition order on the adsorption of PBX on pyrite (a) and talc (b).

Figure 9a,b show the effect of the KG/PBX addition order on the adsorption of KG on pyrite and talc surfaces, respectively. Unlike PBX, the depressant KG is able to adsorb both on pyrite and talc surfaces. From Figure 9a, it is clear that, when KG is added before PBX, the adsorption of KG on the pyrite surface is more than that when PBX is added before $K G$, which is contrary to the adsorption of $\mathrm{PBX}$ on the pyrite surface. However, the addition order of KG/PBX has no effect on the adsorption of $\mathrm{KG}$ on the talc surface, and the adsorption of $\mathrm{KG}$ is increased with the increase of KG concentration. Clearly, the adsorption of KG on the talc surface is more than that on the pyrite surface, which also explains the selective depression of KG towards pyrite and talc. 

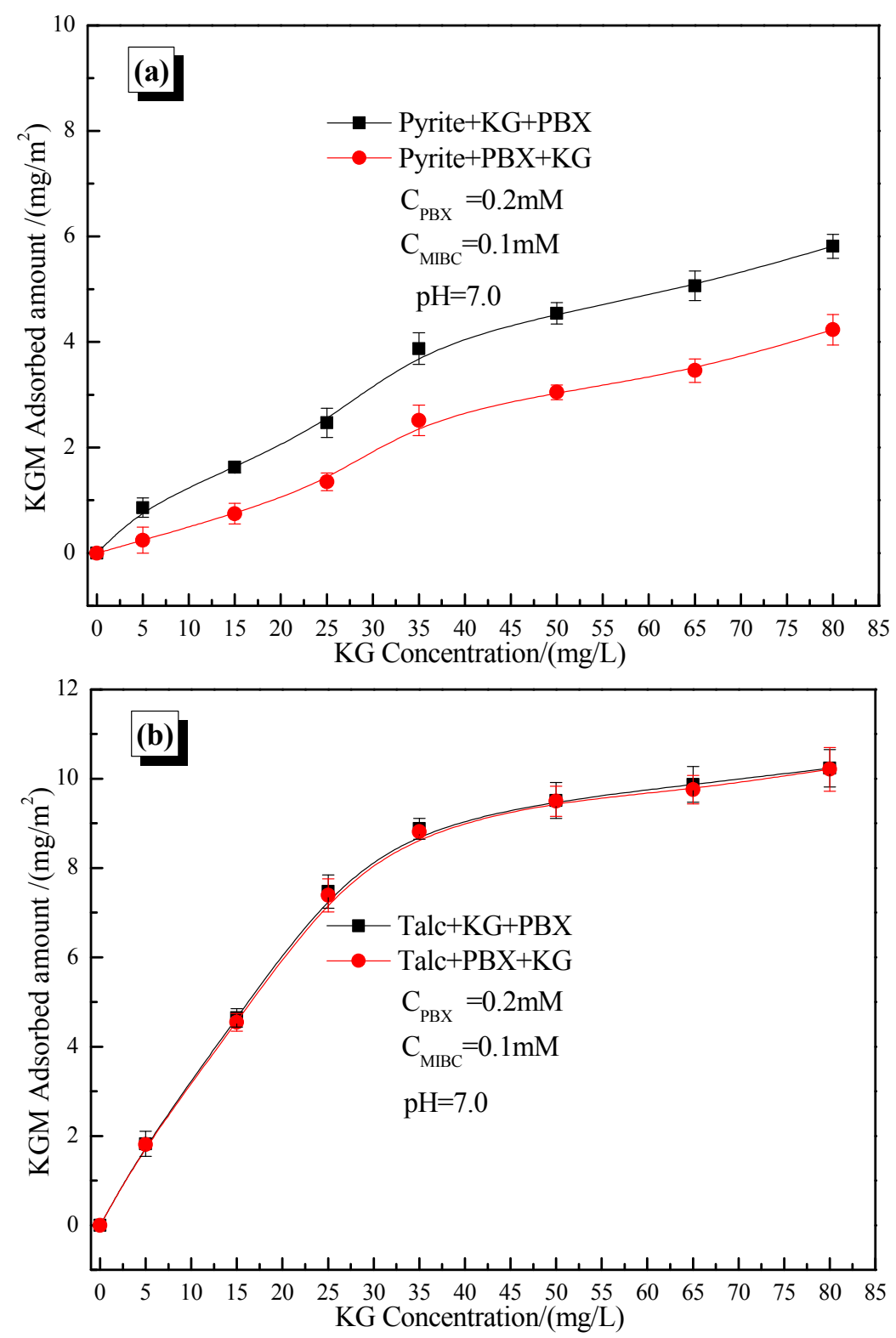

Figure 9. Effect of the KG/PBX addition order on the adsorption of KG on pyrite (a) and talc (b).

\subsection{FTIR Spectra Analysis}

The contact angle results and adsorption test results all prove the selective adsorption property of the reagents on the pyrite and talc surfaces. However, the underlying adsorption mechanism of the reagents on the pyrite and talc surfaces remains unclear. Thus, FTIR experiments were carried out to further analyze the adsorption mechanism.

Figure 10a presents the FTIR spectrum of pyrite after it is conditioned with reagents that are added in different orders. In the IR spectrum of KG, the peaks at 3468 and $2927 \mathrm{~cm}^{-1}$ are the stretching vibration of $-\mathrm{OH}$ and $-\mathrm{CH}_{2}$, respectively. The peak at $1654 \mathrm{~cm}^{-1}$ is attributed to the ring stretching vibration of a carbon oxygen six-member ring [21]. The peak at $1159 \mathrm{~cm}^{-1}$ is produced by the stretching vibration of $\mathrm{C}-\mathrm{O}$, while the peaks at 1079 and $1012 \mathrm{~cm}^{-1}$ belong to the stretching vibration of $\mathrm{C}-\mathrm{O}$ in $-\mathrm{CH}_{2}-\mathrm{OH}$ and $-\mathrm{CH}-\mathrm{OH}[5,22]$. In the IR spectrum of $\mathrm{PBX}$, the peak at $1064 \mathrm{~cm}^{-1}$ is attributed to the $\mathrm{C}=\mathrm{S}$ stretching vibration. The intense peak at $1114 \mathrm{~cm}^{-1}$ belongs to the $\mathrm{C}-\mathrm{O}-\mathrm{C}$ symmetric stretching vibration [23]. 

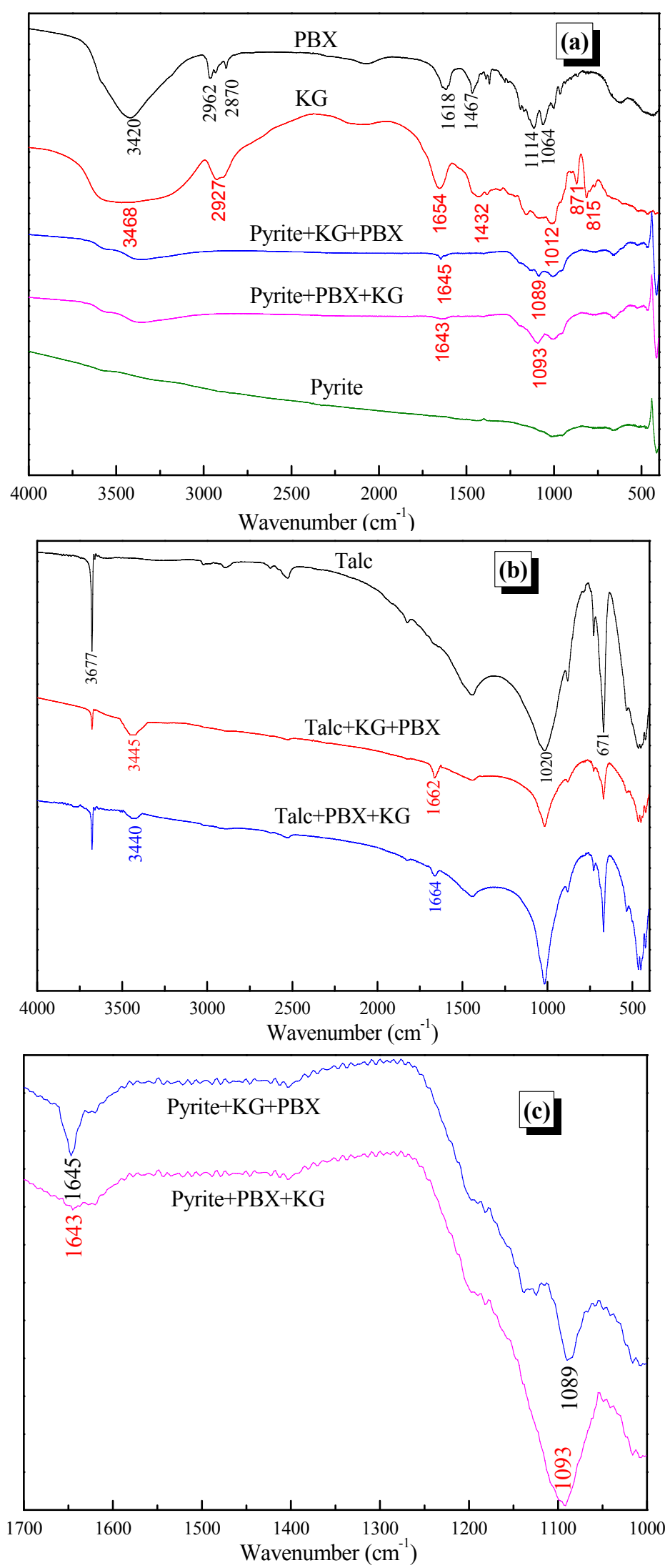

Figure 10. Infrared spectra of pyrite (a) and talc (b) after they are conditioned with reagents that are added in different order; (c) is the enlarged spectra of (a). 
When KG is added before PBX, a new peak at $1645 \mathrm{~cm}^{-1}$ appears in the spectrum of pyrite, which is due to the ring stretching vibration of the carbon oxygen six-member ring in KG. At the same time, a new peak appears at $1089 \mathrm{~cm}^{-1}$, which is the characteristic peak of $C=S$ in the collector PBX [24]. Compared with the peaks of KG and PBX, the new peaks in the spectrum of pyrite are shifted by 9 and $35 \mathrm{~cm}^{-1}$, respectively, which indicates the chemical adsorption of $K G$ and PBX on the pyrite surface. Figure 10c is the enlarged spectra of Figure 10a. It is clear in Figure 10c that, although the same type of peaks at 1643 and $1093 \mathrm{~cm}^{-1}$ appear in the spectrum of pyrite that is pre-adsorbed with PBX, the peak intensity differs from that when KG is added before PBX. Compared with the peak of pyrite treated by adding KG before PBX, the peak intensity at $1643 \mathrm{~cm}^{-1}$ is weakened, while the peak intensity at $1093 \mathrm{~cm}^{-1}$ is enhanced in the spectrum of pyrite that is pre-adsorbed with PBX. Thus, it can be inferred that the adsorption of $\mathrm{KG}$ is weakened and the adsorption of $\mathrm{PBX}$ is strengthened on the pyrite surface by pre-adsorbing pyrite with PBX.

Figure 10b presents the FTIR spectrum of talc after it is conditioned with reagents that are added in different order. Strong peaks of $-\mathrm{OH}$ at and $3445 \mathrm{~cm}^{-1}$ and of the carbon oxygen six-member ring at 1662 and $1664 \mathrm{~cm}^{-1}$ appear in the spectrum of talc that is conditioned with reagents. These data indicate that KG is adsorbed on the surface of talc mainly via chemical adsorption [16]. Considering that the characteristic peaks of talc reacted with PBX are focused on the wavenumbers below $1400 \mathrm{~cm}^{-1}$ and no characteristic peaks of PBX are found in the section, it is reasonable to infer that no PBX is adsorbed on the talc surface $[23,25]$. The FTIR spectra analysis results are consistent with the flotation and adsorption results.

Based on the abovementioned analysis, the schematic illustration of KG and PBX adsorption order on pyrite and talc surfaces is shown in Figure 11. The adsorption and contact angle results show that KG is able to absorb on pyrite and talc surfaces, while PBX can only adsorb on the pyrite surface. It is reasonable to deduce that competitive adsorption of KG and PBX exists on the pyrite surface, while on the talc surface the competitive adsorption does not exist. When pyrite is pre-adsorbed with PBX, the hydrophobicity of pyrite increases, which prevents pyrite from further adsorbing KG that contains hydrophilic groups. A similar situation occurs when KG is added before PBX. However, because only the depressant KG can adsorb on the talc surface, regardless of the order in which the reagents are added, the amount of KG that is adsorbed on the talc surface and the depressive effect of $\mathrm{KG}$ on talc is not affected. Thus, by controlling the adsorption order of reagents on mineral surfaces, we can increase the flotation difference between pyrite and talc.

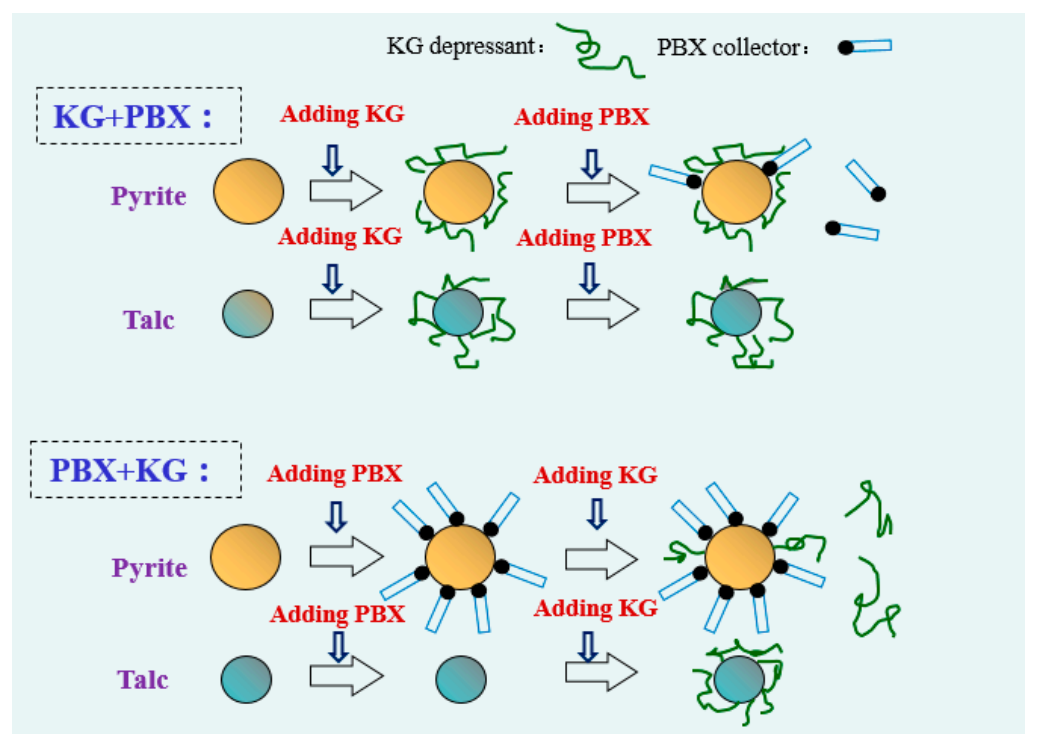

Figure 11. Schematic illustration of the addition order of $K G / P B X$ that affects the reagent adsorption order. 


\section{Conclusions}

Based on the results of this study, the following conclusion can be drawn:

(1) KG is a quality depressant of talc. The addition of KG increases the microflotation recovery difference between pyrite and talc. KG and PBX can adsorb on the surface of pyrite, while only KG can adsorb on the surface of talc.

(2) The addition order of KG and PBX significantly influences the recovery, wettability and reagent adsorption of pyrite, but has little influence on these parameters on talc.

(3) KG adsorbs on pyrite and talc surfaces via a chemical reaction, while PBX only adsorbs on the pyrite surface via a chemical reaction. Competitive adsorption between KG and PBX exists on the surface of pyrite, and pre-adsorbing pyrite with PBX prevents pyrite from continuously adsorbing KG.

(4) By controlling the addition order of KG/PBX, the flotation difference between pyrite and talc increases and the flotation separation of pyrite from talc becomes feasible.

Acknowledgments: The authors would like to thank the National Natural Science Foundation of China (Grant Nos. 51674207, 51304162 and 51504224), the Key Foundation of Natural Scientific Research of the Education Department of Sichuan Province, China (Grant No. 16ZA0130), the Fund of the State Key Laboratory of Mineral Processing (Grant No. BGRIMM-KJSKL-2016-03), the Basic and Public Geology and Mineral Resources Survey Foundation of China Geological Survey (Grant No. DD20160074-6), the Foundation of Key Laboratory of Solid Waste Treatment and Resource Recycle Ministry of Education for Professional Innovation Research Team (Grant No. 14tdgk03) and the Applied Basic Research Foundation of Sichuan Province (Grant No. 2016JY0127) for the financial support.

Author Contributions: Longhua $\mathrm{Xu}$, Yuehua $\mathrm{Hu}$ and Yuexin Han conceived and designed the experiments; Wei Deng and Jia Tian performed the experiments and analyzed the data; Longhua Xu and Yuexin Han contributed reagents and materials; Wei Deng and Longhua $\mathrm{Xu}$ wrote the paper.

Conflicts of Interest: The authors declare no conflict of interest.

\section{References}

1. Douillard, J.M.; Salles, F.; Henry, M.; Malandrini, H.; Clauss, F. Surface energy of talc and chlorite: Comparison between electronegativity calculation and immersion results. J. Colloid Interface Sci. 2007, 305, 352-360. [CrossRef] [PubMed]

2. Farrokhpay, S.; Filippov, L. Challenges in processing nickel laterite ores by flotation. Int. J. Miner. Process. 2016, 151, 59-67. [CrossRef]

3. Liu, G.; Feng, Q.; Ou, L.; Lu, Y.; Zhang, G. Adsorption of polysaccharide onto talc. Miner. Eng. 2006, 19, 147-153. [CrossRef]

4. Xu, L.; Wu, H.; Dong, F.; Wang, L.; Wang, Z.; Xiao, J. Flotation and adsorption of mixed cationic/anionic collectors on muscovite mica. Miner. Eng. 2013, 41, 41-45. [CrossRef]

5. Zhao, K.L.; Gu, G.H.; Wang, H.; Wang, C.L.; Wang, X.H.; Luo, C. Influence of depressant foenum-graecum on the flotation of a sulfide ore which contains hydrophobic gangue. Int. J. Miner. Process. 2015, 141, 68-76. [CrossRef]

6. Beattie, D.A.; Huynh, L.; Kaggwa, G.B.; Ralston, J. Influence of adsorbed polysaccharides and polyacrylamides on talc flotation. Int. J. Miner. Process. 2006, 78, 238-249. [CrossRef]

7. Beattie, D.A.; Huynh, L.; Kaggwa, G.B.; Ralston, J. The effect of polysaccharides and polyacrylamides on the depression of talc and the flotation of sulphide minerals. Miner. Eng. 2006, 19, 598-608. [CrossRef]

8. Leung, A.; Wiltshire, J.; Blencowe, A.; Fu, Q.; Solomon, D.H.; Qiao, G.G. The effect of acrylamide-covinylpyrrolidinone copolymer on the depression of talc in mixed nickel mineral flotation. Miner. Eng. 2011, 24, 449-454. [CrossRef]

9. Bagci, E.; Ekmekci, Z.; Bradshaw, D. Adsorption behaviour of xanthate and dithiophosphinate from their mixtures on chalcopyrite. Miner. Eng. 2007, 20, 1047-1053. [CrossRef]

10. Bicak, O.; Ekmekci, Z.; Bradshaw, D.J.; Harris, P.J. Adsorption of guar gum and CMC on pyrite. Miner. Eng. 2007, 20, 996-1002. [CrossRef] 
11. López Valdivieso, A.; Celedón Cervantes, T.; Song, S.; Robledo Cabrera, A.; Laskowski, J.S. Dextrin as a non-toxic depressant for pyrite in flotation with xanthates as collector. Miner. Eng. 2004, 17, 1001-1006. [CrossRef]

12. Garcia Vidal, C.A.; Pawlik, M. Molecular weight effects in interactions of guar gum with talc. Int. J. Miner. Process. 2015, 138, 38-43. [CrossRef]

13. Khraisheh, M.; Holland, C.; Creany, C.; Harris, P.; Parolis, L. Effect of molecular weight and concentration on the adsorption of CMC onto talc at different ionic strengths. Int. J. Miner. Process. 2005, 75, 197-206. [CrossRef]

14. McFadzean, B.; Dicks, P.; Groenmeyer, G.; Harris, P.; O'Connor, C. The effect of molecular weight on the adsorption and efficacy of polysaccharide depressants. Miner. Eng. 2011, 24, 463-469. [CrossRef]

15. McFadzean, B.; Groenmeyer, G. Selective molecular weight adsorption from polydisperse polysaccharide depressants. Miner. Eng. 2015, 77, 172-178. [CrossRef]

16. Zhao, K.; Gu, G.; Wang, C.; Rao, X.; Wang, X.; Xiong, X. The effect of a new polysaccharide on the depression of talc and the flotation of a nickel-copper sulfide ore. Miner. Eng. 2015, 77, 99-106. [CrossRef]

17. Wiese, J.; Harris, P.; Bradshaw, D. The response of sulphide and gangue minerals in selected Merensky ores to increased depressant dosages. Miner. Eng. 2007, 20, 986-995. [CrossRef]

18. Feng, B.; Feng, Q.; Lu, Y.; Gu, Y. The effect of PAX/CMC addition order on chlorite/pyrite separation. Miner. Eng. 2013, 42, 9-12. [CrossRef]

19. Feng, B.; Lu, Y.; Luo, X. The effect of quartz on the flotation of pyrite depressed by serpentine. J. Mater. Res. Technol. 2015, 4, 8-13. [CrossRef]

20. Mu, Y.; Peng, Y.; Lauten, R.A. The depression of pyrite in selective flotation by different reagent systems-A Literature review. Miner. Eng. 2016, 96, 143-156. [CrossRef]

21. Xu, L.; Hu, Y.; Tian, J.; Wu, H.; Wang, L.; Yang, Y.; Wang, Z. Synergistic effect of mixed cationic/anionic collectors on flotation and adsorption of muscovite. Colloids Surf. A 2016, 492, 181-189. [CrossRef]

22. Wang, J.; Somasundaran, P.; Nagaraj, D.R. Adsorption mechanism of guar gum at solid-liquid interfaces. Miner. Eng. 2005, 18, 77-81. [CrossRef]

23. Zhang, Y.H.; Cao, Z.; Cao, Y.D.; Sun, C.Y. FTIR studies of xanthate adsorption on chalcopyrite, pentlandite and pyrite surfaces. J. Mol. Struct. 2013, 1048, 434-440. [CrossRef]

24. Chiem, L.T.; Huynh, L.; Ralston, J.; Beattie, D.A. An in situ ATR-FTIR study of polyacrylamide adsorption at the talc surface. J. Colloid Interface Sci. 2006, 297, 54-61. [CrossRef] [PubMed]

25. Wang, Z.; Qian, Y.; Xu, L.H.; Dai, B.; Xiao, J.H.; Fu, K. Selective chalcopyrite flotation from pyrite with glycerine-xanthate as depressant. Miner. Eng. 2015, 74, 86-90. [CrossRef]

(C) 2017 by the authors. Licensee MDPI, Basel, Switzerland. This article is an open access article distributed under the terms and conditions of the Creative Commons Attribution (CC BY) license (http:/ / creativecommons.org/licenses/by/4.0/). 